\title{
Changes in the composition of the non-copepod zooplankton assemblage in St Helena Bay (southern Benguela ecosystem) during a six day drogue study
}

\author{
M. J. Gibbons ${ }^{1, *}$, N. Gugushe ${ }^{1}$, A. J. Boyd ${ }^{2}$, L. J. Shannon ${ }^{2}$, B. A. Mitchell-Innes ${ }^{2}$ \\ ${ }^{1}$ Zoology Department, University of the Western Cape, Private Bag X17, Bellville 7535, South Africa \\ ${ }^{2}$ Sea Fisheries Research Institute, Private Bag X2, Roggebaai 8012, South Africa
}

\begin{abstract}
Marked changes in the composition and structure of the non-copepod components of a zooplankton assemblage were observed during the course of a $6 \mathrm{~d}$ drogue study in the southern Benguela ecosystem. These changes reflected in part the spiraled nature of the drogue and were linked to the settlement of meroplankton from the surface waters and to the nocturnal recruitment, and subsequent accumulation, of migratory holoplankton and zoobenthos from depth. The presence of large numbers of benthic species in the plankton is hypothesised to reflect their upward migration at night owing to food limitation, since little of the overlying diatom bloom was sedimenting out. The presence of low-oxygen bottom water is hypothesised to account for the failure of the detritivorous zoobenthos to return to the seafloor during the day. The results suggest that the composition of zooplankton assemblages in upwelling areas is not only driven by the dynamism of the physical environment, but that, under certain circumstances, a more subtle interplay between the biological and physical environment may result in strong changes in assemblage composition.
\end{abstract}

KEY WORDS: Zooplankton A Assemblage composition - Southern Benguela Zoobenthos - Cumacea Phytoplankton aggregates $\cdot$ Low-oxygen water

\section{INTRODUCTION}

Zooplankton assemblages in the waters of the central ocean basins are typically diverse and display a constancy of structure and composition that spans a wide range of temporal and spatial scales (McGowan \& Walker 1979). In upwelling areas, by contrast, assemblages are generally of low diversity (Gibbons \& Hutchings 1996), and there is often little similarity between samples of zooplankton collected a few days apart in time and a few kilometres apart in distance (Hayward 1986, Hutchings 1988). Differences in the diversity and complexity of the assemblages in the 2 areas, as well as differences in the constancy of assemblage structure,

•E-mail: mgibbons@uwc.ac.za reflect differences in the physical environment. The stability and age of the oligotrophic ocean basins have allowed biological processes such as competition and predation to shape the structure of zooplankton assemblages (McGowan \& Walker 1979, Hayward 1980 Hopkins et al, 1989, Flock \& Hopkins 1992). Upwelling regions, on the other hand, are both physically dynamic and of relatively recent origin (Shannon 1985), so that biological processes can play only a limited role in shaping assemblage structure.

Although the physical environment essentially limits the complexity of the assemblage that can evolve in upwelling areas, biological processes are nevertheless thought to structure the phytoplankton communities, and ecological succession has been documented (Pitcher et al. 1991). Newly upwelled water is characterised by low chlorophyll biomass and phytoplankton 
assemblages which are dominated by small diatoms. As the water column stabilises and moves offshore by Ekman transport, chlorophyll biomass increases and communities become dominated by large and chainforming diatoms. With an increase in stratification and a progressive loss of nutrients from the surface waters, diatoms are replaced by dinoflagellates which in turn give way to small naked flagellates (Pitcher et al. 1991, 1992). This type of succession is autochthonous, because the upwelled water itself contains the seeds of all the species that comprise the successional sequence.

There is little comparative information for zooplankton. Evidence of autochthonous changes in zooplankton assemblage composition that mirror changes in the phytoplankton is not to be expected given the basic lag in response times of phytoplankton and zooplankton (Hutchings 1992). That is not to say, however, that changes in the structure and composition of zooplankton assemblages might not occur following an upwelling event, because animals could migrate into, and out of, a maturing water mass in response to biological and physical cues. Changes in the composition of the non-copepod components of the zooplankton assemblage in St Helena Bay, South Africa, were investigated to explore this possibility, following an upwelling event.

\section{MATERIALS AND METHODS}

A 6 d drogue study was conducted in St Helena Bay ( $32^{\circ} 35^{\prime} \mathrm{S}, 18^{\circ} 07^{\prime} \mathrm{E}$ ) between 20 and 26 February 1995 from the FRS 'Africana'. A weighted $2 \mathrm{~m}$ tetrahedral drogue was positioned at $10 \mathrm{~m}$ depth and was connected via line and shock-cord to a surface buoy equipped with a radar reflector and flashing light. The drogue was tracked via the ship's GPS-interfaced radar.

Environmental variables and plankton samples were collected at regular intervals (stations) throughout the day and night over this period, close to the position of the drogue. Currents were measured using an RD Instruments $150 \mathrm{kHz}$ acoustic doppler current profiler (ADCP) at each station. A Neil Brown Mk 3b conductivity-temperature-depth (CTD) instrument with a 12 bottle rosette was lowered from the surface to near the bottom at each station to provide profiles of salinity and temperature. Water samples were taken for the determination of dissolved oxygen at regular depth intervals. The concentration of dissolved oxygen was determined by the Winkler method, using azide to counteract the possible presence of nitrites. Fluorescence profiles were obtained using a Chelsea Instruments Aquatracka submersible fluorometer mounted on a magnum rosette, and water samples were collected at the surface and at the fluorescence maximum for determination of chlorophyll a. Chlorophyll samples were analysed within $6 \mathrm{~h}$ following the method of Parsons et al. (1984).

Zooplankton were collected throughout the day and night using both depth-integrating vertical nets and depth-stratified nets. The paired vertical Bongo nets were fitted with $200 \mu \mathrm{m}$ mesh and were hauled from $5 \mathrm{~m}$ above the seafloor to the surface at $1 \mathrm{~m} \mathrm{~s}^{-1}$. A mechanical flowmeter was fitted above the mouth of 1 of the nets to determine the volume of water filtered. A $200 \mu \mathrm{m}$ meshed $1 \mathrm{~m}^{2}$ multiple opening-closing rectangular midwater trawl (RMT $1 \times 6$ ) was towed obliquely at 2 knots over 5 depth strata from just above the bottom to the surface. These strata were approximately $60-40,40-30$, $30-20,20-10$ and $10-0 \mathrm{~m}$. Flow rate was estimated using a flowmeter mounted above the mouth of the net, and $100 \%$ efficiency was assumed for the tows which were of approximately equal, short duration $(<60 \mathrm{~s})$. Upon retrieval, the zooplankton samples were preserved in $4 \%$ buffered saline formalin for later counting.

Owing to their small size and generally delicate nature, the larvae of bivalves, gastropods, bryozoans (cyphonautes) and polychaetes were counted from the vertical Bongo samples only. As most meroplankton are likely to be weak swimmers, their collection by vertical nets should have been quantitative. Otherwise, all non-copepod zooplankton were counted from each RMT $1 \times 6$ sample within 2 mo of return to the laboratory. No copepods were identified and counted, although they were collected. When collections were large, subsamples were taken using a Folsom splitter, and a minimum of 100 individuals was counted. Data were standardised to numbers per $\mathrm{m}^{3}$ and $\mathrm{m}^{2}$ using flowmeter data. To provide average estimates of population size during the night and day, the different separate nighttime and daytime samples were combined.

The mean vertical position (weighted mean depth, WMD) of dominant taxa in the water column at any one time was determined using the method of Pearre (1973)

$$
\mathrm{WMD}=\sum n_{i} d_{i} / \sum n_{i}
$$

where $n_{1}$ is the number of individuals per $\mathrm{m}^{3}$ within a net stratum and $d_{i}$ is the mid-depth of that depth stratum

To determine changes in the structure and composition of zooplankton assemblages over the study period samples were subject to classification analysis following root-root transformation (Clarke \& Warwick 1994). This analysis was based on link-average grouping using the Bray-Curtis similarity indices, and was computed using the 'Plymouth Routines In Multivariate Ecological Research' (PRIMER v4; Carr 1997). It should 
be noted that only those species whose abundance represented more than $0.1 \%$ of the assemblage were included in these analyses. A classification analysis was also conducted on the species, to determine how species grouped together through time.

\section{RESULTS}

\section{Water movement}

The drogue at $10 \mathrm{~m}$ depth moved in a mean northerly direction into progressively deeper water (with an average speed of $5 \mathrm{~cm} \mathrm{~s}^{-1}$ ) during the first $4 \mathrm{~d}$ of the study (Fig. 1). The track during this phase (based on 1 to $3 \mathrm{~h}$ positions) also shows the response of the upper layer to the diumally varying winds, which

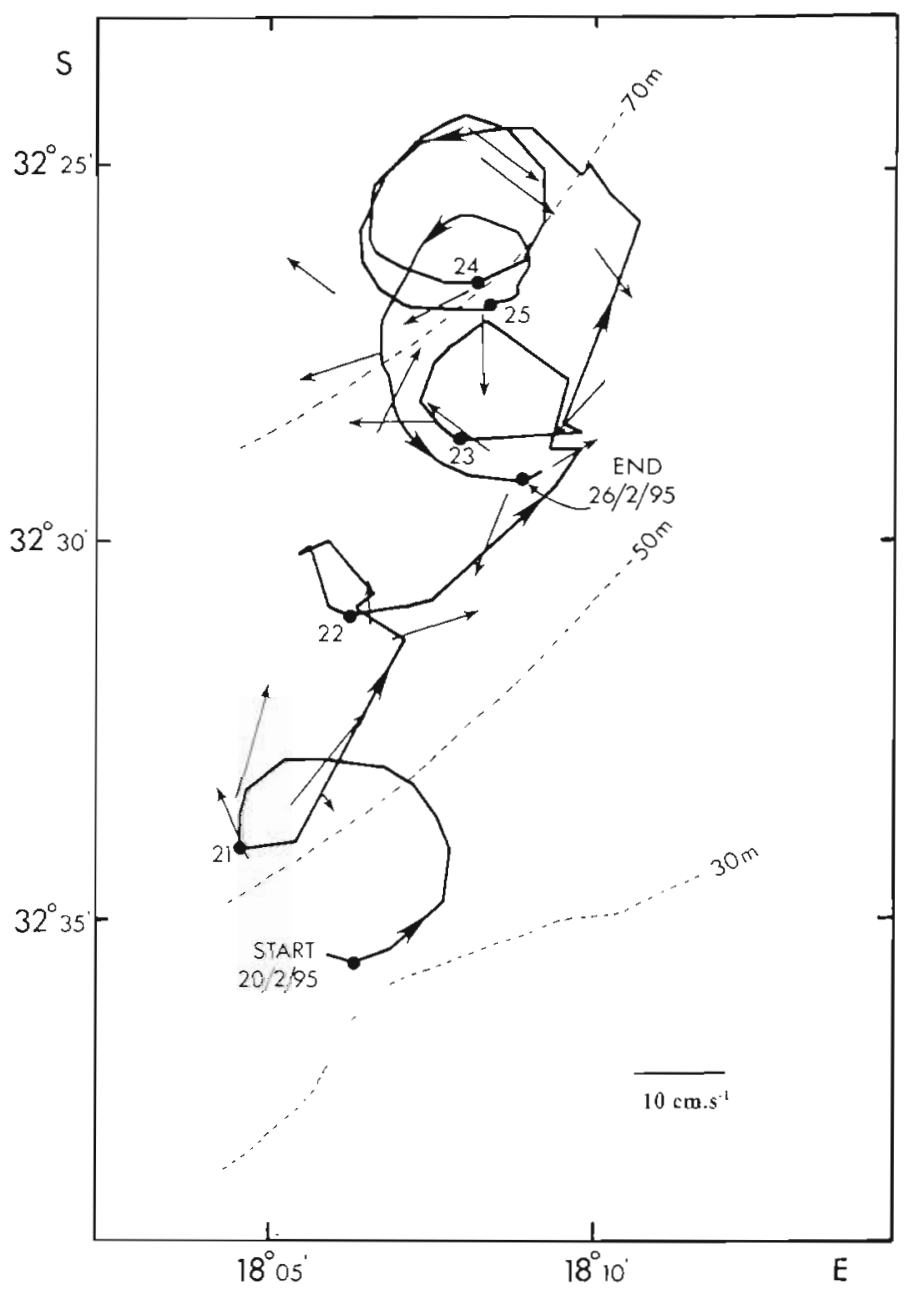

Fig. 1. Track of $10 \mathrm{~m}$ drogue from 20 to 26 February 1995 in St Helena Bay $\left(32^{\circ} 35^{\prime} \mathrm{S}, 18^{\circ} 07^{\prime} \mathrm{E}\right)$. Dots: position of the drogue during the morning station (09:00 to 10:30 h). Vectors: current recorded by the ADCP at $34 \mathrm{~m}$ depth at each station. Bathymetric depth contours are also shown reached a maximum in the late afternoon. The drogue track shows a tightening, anticlockwise curvature due to inertial effects on the decelerating current. The last $3 \mathrm{~d}$ of the study were conducted in conditions of low wind speed. The drogue described almost perfect inertial circles, although moving slowly southwards during the last $36 \mathrm{~h}$, together with the lower water layer, as shown by the ADCP measurements (Fig. 1). These results suggest the absence of a synoptic upwelling event or shelf-wave forcing, which typically dominate the currents on the west coast shelf (Nelson 1989).

Measurements of vertical shear in horizontal velocity were obtained both from optical tracking of small drogues in the upper $20 \mathrm{~m}$ (as done by Boyd 1982 of the Cape Peninsula) and from the ADCP measurements carried out whilst the vessel was stationary. These revealed significant shear through the water column, often reaching a maximum of $10 \mathrm{~cm} \mathrm{~s}^{-1} 10 \mathrm{~m}^{-1}$ in the upper $30 \mathrm{~m}$. On 24 and 25 February (Days 5 and 6), additional drogues were released at 2 and $20 \mathrm{~m}$ and these showed 'independent' inertial circles at these depths, in addition to those described at $10 \mathrm{~m}$. The period of rotation at all depths was close to that expected theoretically at $33^{\circ} \mathrm{S}$ (22 h), but the velocities were not in phase with each other.

\section{Structure and properties of the water column}

The thermal structure of the water column changed only subtly during the study (Fig. 2A), with the position of the base of the thermocline (marked by the $9.5^{\circ} \mathrm{C}$ isotherm at 25 to $35 \mathrm{~m}$ ) and the temperatures below it remaining almost constant. The upper mixed layer, above the $12^{\circ} \mathrm{C}$ isotherm at 15 to $20 \mathrm{~m}$, was very weakly stratified until 23 and 24 February (Days 4 and 5) when the temperature in the upper $15 \mathrm{~m}$ warmed by 1 to $2^{\circ} \mathrm{C}$ and the upper layer became more stratified. The entire water column was isohaline for the whole period, with a mean salinity of $34.7 \mathrm{ppt}$. This suggests that while current shear may have been ubiquitous in the upper layer, it operated on a small scale and there was no noticable advection of different water bodies to the vicinity of the drogue.

The oxygen time-series showed well-oxygenated water in the upper $10 \mathrm{~m}$, followed by an abrupt decrease to values less than $1 \mathrm{ml} \mathrm{l}^{-1}$ below $30 \mathrm{~m}$ (Fig. 2B). Although anoxic conditions were not recorded, even at the bottom, it is clear that low-oxygen water was generally present over the seabed during the daytime period (see data in Fig. 2B). Diurnal variations in temperature can be discerned on Days 1, 3, 4 and 5, as daytime warming was followed by an uplifting of the isotherms in the late afternoon and evening (Fig. 2A). Similarly, several maxima and minima in surface oxygen values 

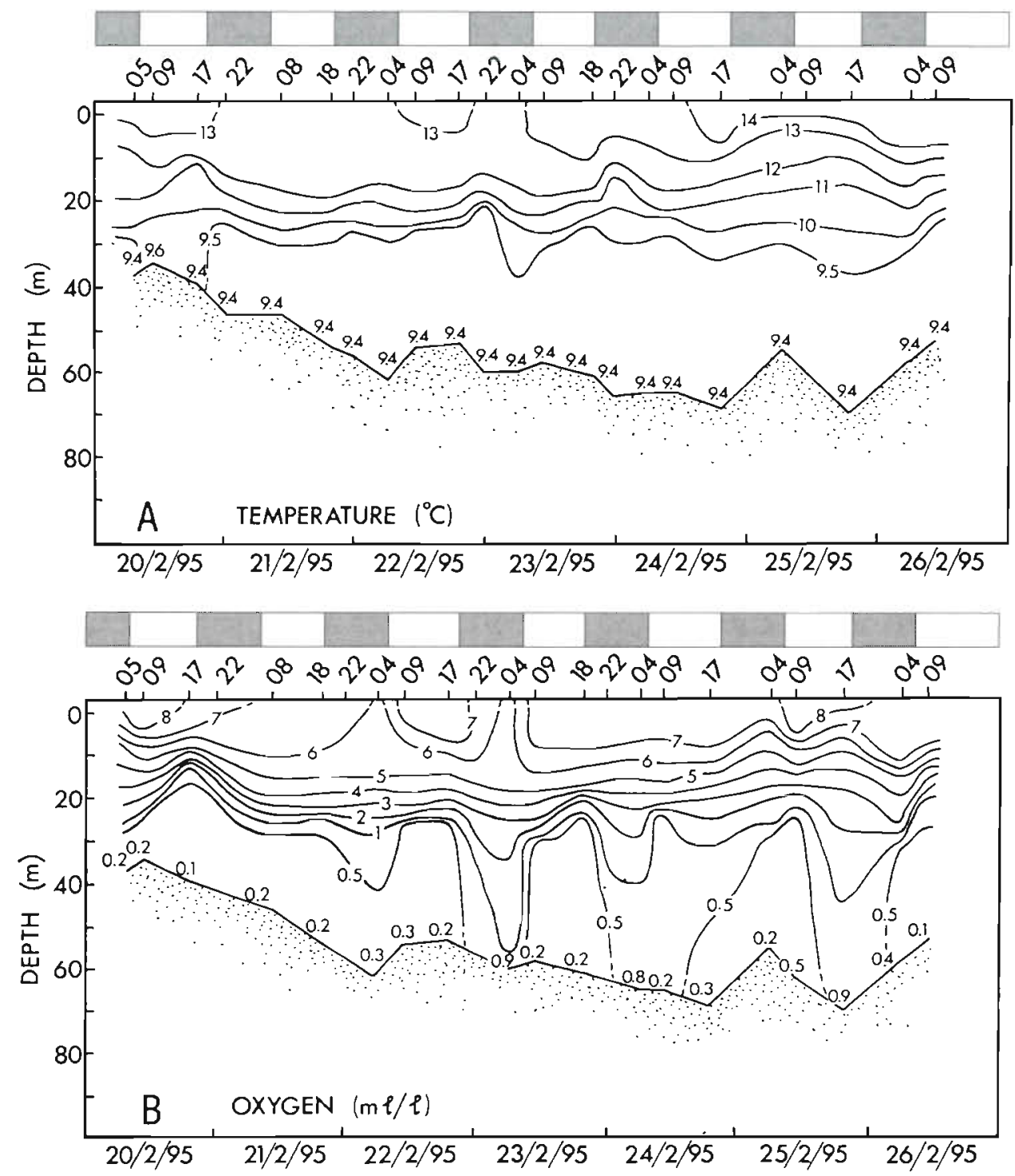

Fig. 2. Temporal variation in the vertical distribution of (A) temperature and (B) oxygen over the study period. Values on upper edge of panels are hours at which sampling occurred (light and dark periods also shown)

occurred during the day and in the early morning respectively (Fig. 2B). This is due to daytime production and nocturnal respiration (Bailey \& Chapman 1991).

\section{Phytoplankton}

Assemblages were dominated by diatoms, especially Chaetoceros spp., although populations of the dinoflagellate Ceratium lineatum began to develop in the stratified surface waters by Day 6 (25 February). The depth-integrated pigment biomass was ca $500 \mathrm{mg}$ chlorophyll $\mathrm{m}^{-2}$, and remained at this level throughout the study. The concentration of chlorophyll reached a maximum of $-30 \mathrm{mg} \mathrm{m}^{-3}$, and although the depth of the fluorescence maximum decreased slightly with time it did not pass through the thermocline (Fig. 3).

\section{Non-copepod zooplankton and meroplankton}

A total of 31 distinct non-copepod taxa were recorded between 20 and 25 February 1995 (Table 1). Assemblages at the start of the study (Day 1) were dominated by meroplanktonic taxa (including cnidarians) and larval chaetognaths, but these were replaced by gammarid amphipods, mysids, cumaceans and euphausiids as well as adult Sagitta friderici by the end (Day 6).

Although the similarity amongst the samples was fairly high, distinct groups that corresponded to samples taken between Days 1 and 4 (20 to 23 February) and between Days 5 and 6 (24 to 25 February) could be readily distinguished (Fig. 4 ).

The classification analysis of the major taxa revealed 2 major groups which could be distinguished at the $35 \%$ level of similarity (Fig. 5). Group A taxa were all 


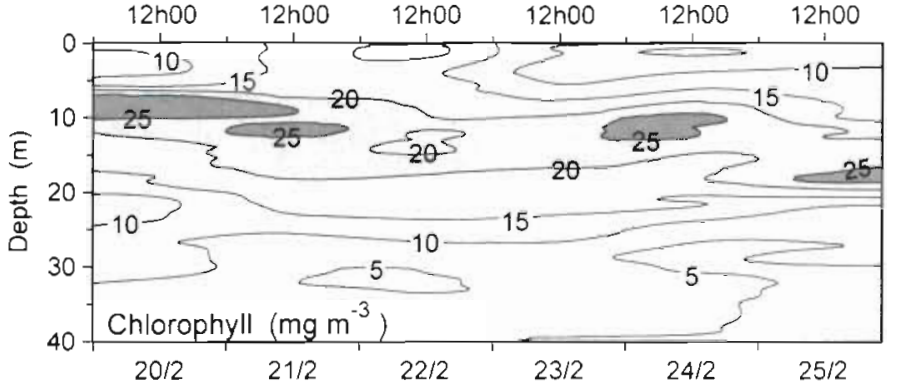

Fig. 3. Temporal variation in the vertical distribution of chlorophyll over the study period

those which were rare or absent at the start of the study but whose numbers increased to peak at the end (Fig. 6A), while Group B taxa were generally recorded throughout the study period. Within Group B, 3 clusters of species are evident, each of which showed

Table 1. Estimated abundance of all non-copepod zooplankton taxa at the start and end of the study period. Also shown are the mean occupational depths (WMD) by night and day for the dominant taxa which were used in the analysis of assemblage composition (see Figs. 4 \& 5). -: data too few; ?: no depth data as taxa counted from vertical Bongo nets

\begin{tabular}{|lrrrr|}
\hline & \multicolumn{2}{c}{ Abundance $\left(\mathrm{m}^{-2}\right)$} & \multicolumn{2}{c|}{ WMD } \\
& Start & End & Day & Night \\
\hline Diastylis algoae & & & & \\
Iphinoe fagei & 413.7 & 1251.5 & 28.1 & 36.7 \\
Gastrosaccus brevifissura & 6.0 & 0.0 & - & - \\
Erythrops bidentata & 0.4 & 30.5 & 10.6 & 29.3 \\
Euphausia lucens & 0.0 & 6.4 & - & - \\
Decapod larvae & 0.0 & 4576.4 & 24.7 & 21.4 \\
Themisto gaudichaudii & 6.2 & 1313.6 & 23.2 & 34.0 \\
Hyperia sp. & 1.8 & 3796.4 & 18.5 & 16.2 \\
Paramoera capensis & 14.5 & 4.8 & - & - \\
Monoculodopsis longimana & 1914.5 & 4185.9 & 24.5 & 32.1 \\
Atylus gultatus & 24.7 & 28.8 & 32.9 & 31.0 \\
Westwoodilla manta & 121.6 & 94.5 & 21.9 & 30.2 \\
Ampelisca sp. & 0.0 & 9.5 & - & - \\
Ostracod & 0.9 & 0.3 & - & - \\
Clytia sp. & 12.7 & 0.1 & - & - \\
Bougainvillia sp. & 567.2 & 50.8 & 15.5 & 15.8 \\
Proboscodactyla menoni & 343.5 & 67.0 & 14.1 & 10.8 \\
Leuckartiara octna & 21.8 & 8.8 & - & - \\
Euphysa aurata & 16.7 & 27.0 & - & - \\
Obelia sp. & 7.3 & 7.9 & - & - \\
Other Medusae & 180.3 & 0.5 & 15.8 & 13.8 \\
Beroe sp. & 32.7 & 8.4 & - & - \\
Pleurobrachia pileus & 61.4 & 84.6 & 13.5 & 17.4 \\
Sagitta friderici & 771.0 & 3470.1 & 19.9 & 30.1 \\
Sagitta larvae & 13182.8 & 95101.7 & 13.8 & 17.1 \\
Sagitta tasmanica & 144052.1 & 95670.7 & 8.6 & 9.7 \\
Megalopa & 0.8 & 363.0 & 35.3 & 36.1 \\
Gastropod larvae & 0.0 & 2.9 & - & - \\
Ciphonaute larvae & 700.7 & 319.6 & $?$ & $?$ \\
Polychaete larvae & 428.5 & 566.0 & $?$ & $?$ \\
Bivalve larvae & 3781.5 & 1689.4 & $?$ & $?$ \\
& 198381.7 & 22425.6 & $?$ & $?$ \\
\hline
\end{tabular}

slightly different trends of changing abundance through the study. The taxa in Group BI were all meroplanktonic, and all showed a decrease in abundance through time (Fig. 6B), while the taxa in Group BII were either holoplanktonic or benthic and showed a consistent increase in abundance (Fig. 6C). The taxa that comprised Group BIII were of mixed life-history strategy; most were meroplanktonic and all showed variable abundances through time (Fig. 6D).

Although there were no significant changes in the mean vertical distribution of the major taxa over the diel cycle (Table 1), there was a tendency for the WMD of the benthic taxa in Groups A and BII to be deeper at night than by day. Such changes were associated with simultaneous nocturnal increases in abundance (as e.g. Fig. 6A). Interestingly, many of these same species showed a progressive deepening of the mean depth of occupation (especially at night) through the study period (Fig. 7), which mirrored not only increases in abundance, but also a warming of the surface layer (Fig. 2A). The exception to this pattern was Sagitta friderici which, like the taxa in Groups BI and BIII, showed no clear trends in vertical position.

\section{DISCUSSION}

\section{Physical environment}

For currents to be dominated by diurnally varying winds and inertial oscillations, significant upwelling or downwelling events (as well as advection due to shelf waves) need to be absent. This in turn depends on both the degree of synoptic scale forcing at the time, and on the exposure of the location to such forcing. The St Helena Bay area is shallow and can be regarded as sheltered in this respect. Late summer and autumn are characterised by decreased upwelling winds and increased stability, and are often associated with red tides. The physical environment during February 1995 was notable in respect of invariant salinity and lower-layer temperatures (Fig. 2A), and the absence of mesoscale forcing or consistent density-driven flow.

We suggest that the path of the drogue at $10 \mathrm{~m}$ can be regarded as a good indication of upper-layer water movement throughout the study period, despite the cyclical velocity shears that were observed, because of the major stratification occurring deeper (between 15 and $35 \mathrm{~m}$ ). Boyd (1983) found a very similar response of near-surface drogues 


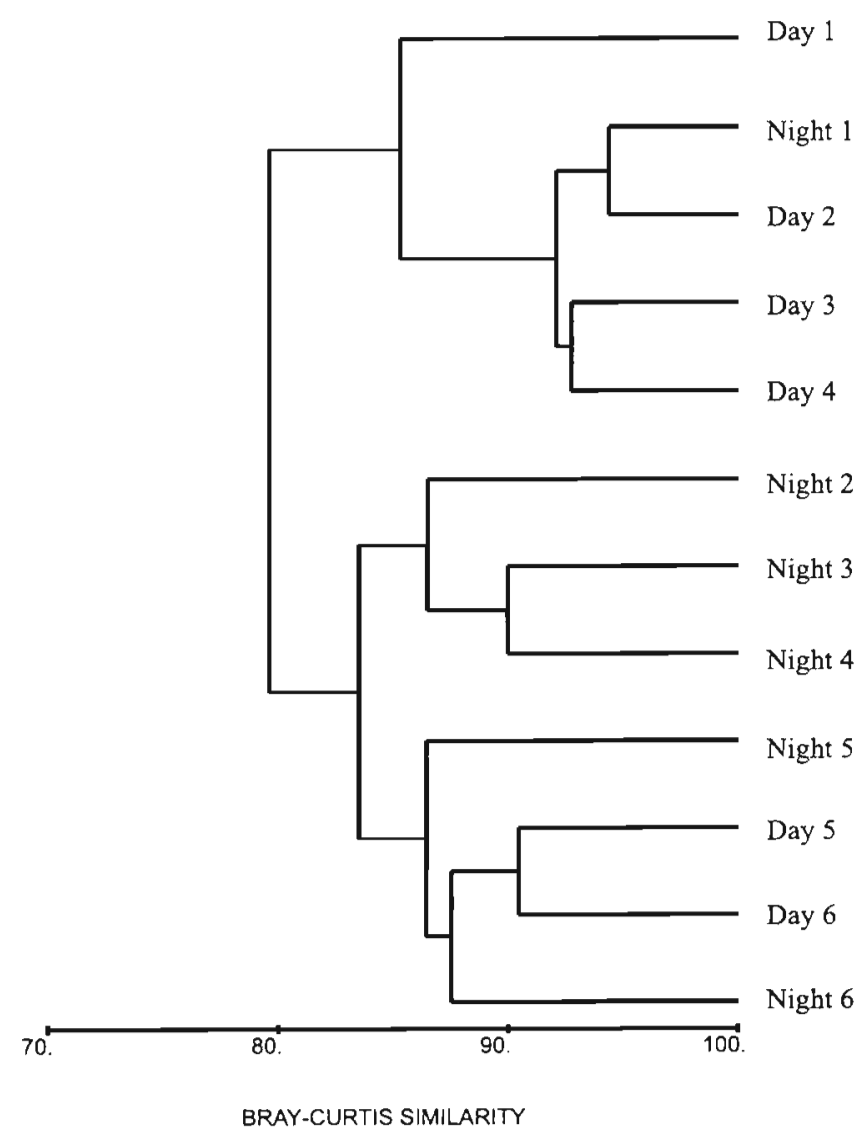

Fig. 4. Dendrogram of the percent similarity between noncopepod zooplankton samples collected during the day and night over the $6 \mathrm{~d}$ study period. Day 1: 20 February 1995. Day 2: 21 February 1995, etc. Night 1: 20-21 February 1995, Night 2: 21-22 February 1995, etc. To simplify interpretation of analysis, assemblages were composed of only those 'major' non-copepod zooplankton species indicated in Table 1

(above a thermocline at $8 \mathrm{~m}$ depth) to diurnal wind forcing in a shallow, sheltered upwelling area at $22^{\circ} \mathrm{S}$ off central Namibia. While drogues below the initial stratification showed weak longshore flow, when wind forcing ceased inertial circles were also observed at different depths. No evidence of semi-diurnal periodicity, indicative of a tidal component, was noted.

The major implication of the above phenomena is a relatively low level of vertical mixing, and this sets the scene for a focus on biological interactions. These interactions could, in fact, have been facilitated by the horizontally circulating layers of water which increased the potential for interaction between species in different parts of the water column. The possibility of a progressive advection of lower layer waters (with different biological properties) into the sampling reference below the drogue exists, but this is not suggested by either the invariant salinity or by the temperature and oxygen measurements (Fig. 2).

\section{Zooplankton assemblages}

The permanent members of the non-copepod zooplankton assemblage described here are routinely collected from the southern Benguela region. Indeed, species such as Sagitta tasmanica, S. friderici, Euphausia lucens and Themisto gaudichaudii have been described as characteristic components of the nearshore biota (Gibbons \& Hutchings 1996). It should be noted that while the abundance of most of these species falls within reported ranges (Gibbons et al. 1992), the numbers of $S$. friderici were remarkably high. The meroplanktonic cnidarians and holoplanktonic ctenophores observed here have also been reported previously (Pagés et al. 1991, Pagés 1992), although the peak numbers attained by Pleurobrachia pileus represent a local maximum that may be partially attributable to the sheltered nature of St Helena Bay. However, departures from normal assemblage composition are observed in the variety, abundance and rel-

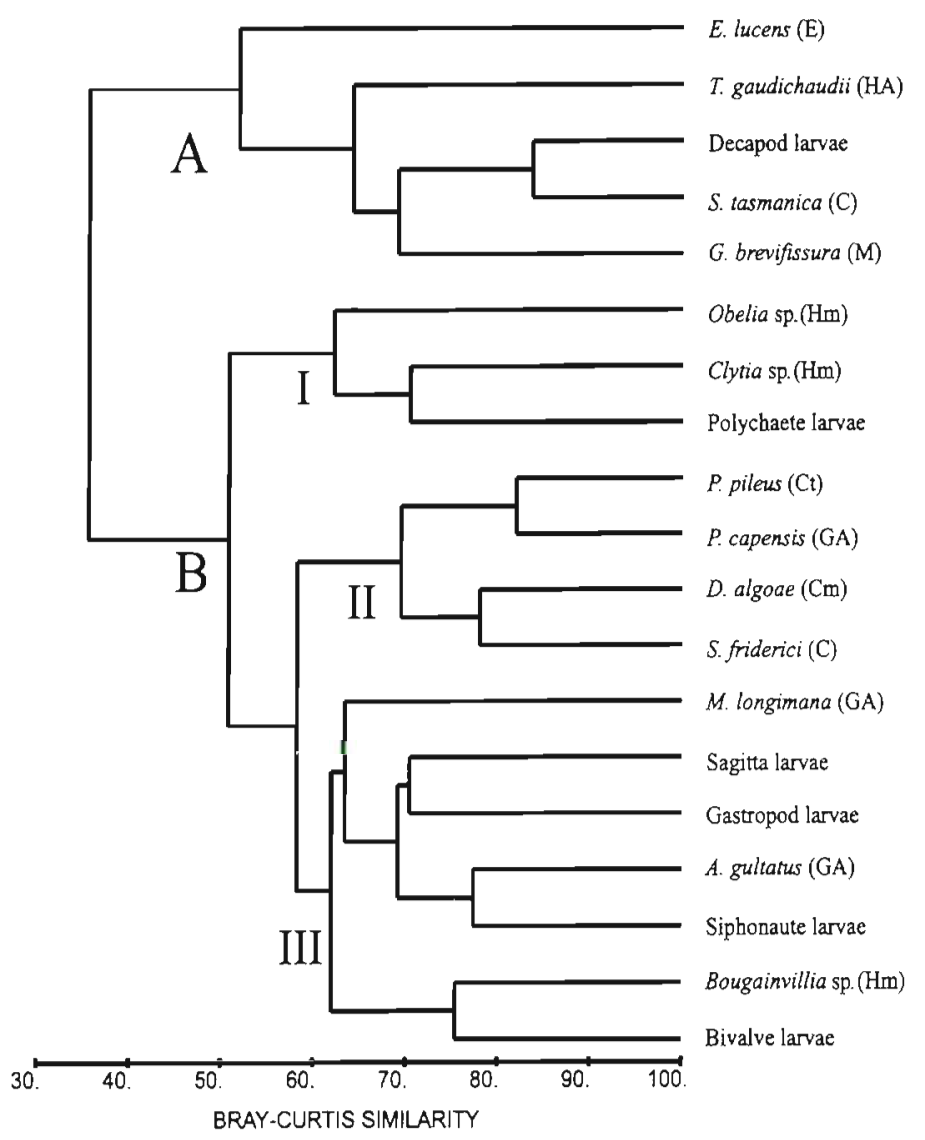

Fig. 5. Dendrogram of the percent similarity amongst the 'major' non-copepod zooplankton taxa fincluding meroplanktonic forms). E: euphausiid, HA: hyperiid amphipod, D: decapod larvae, C: chaetognath, Ct: ctenophore, M: mysid, GA: gammarid amphipod, $\mathrm{Cm}$ : cumacean, Hm: hydomedusa. See Table 1 for full species names. Groups A and BI-BIIl are discussed in the text 

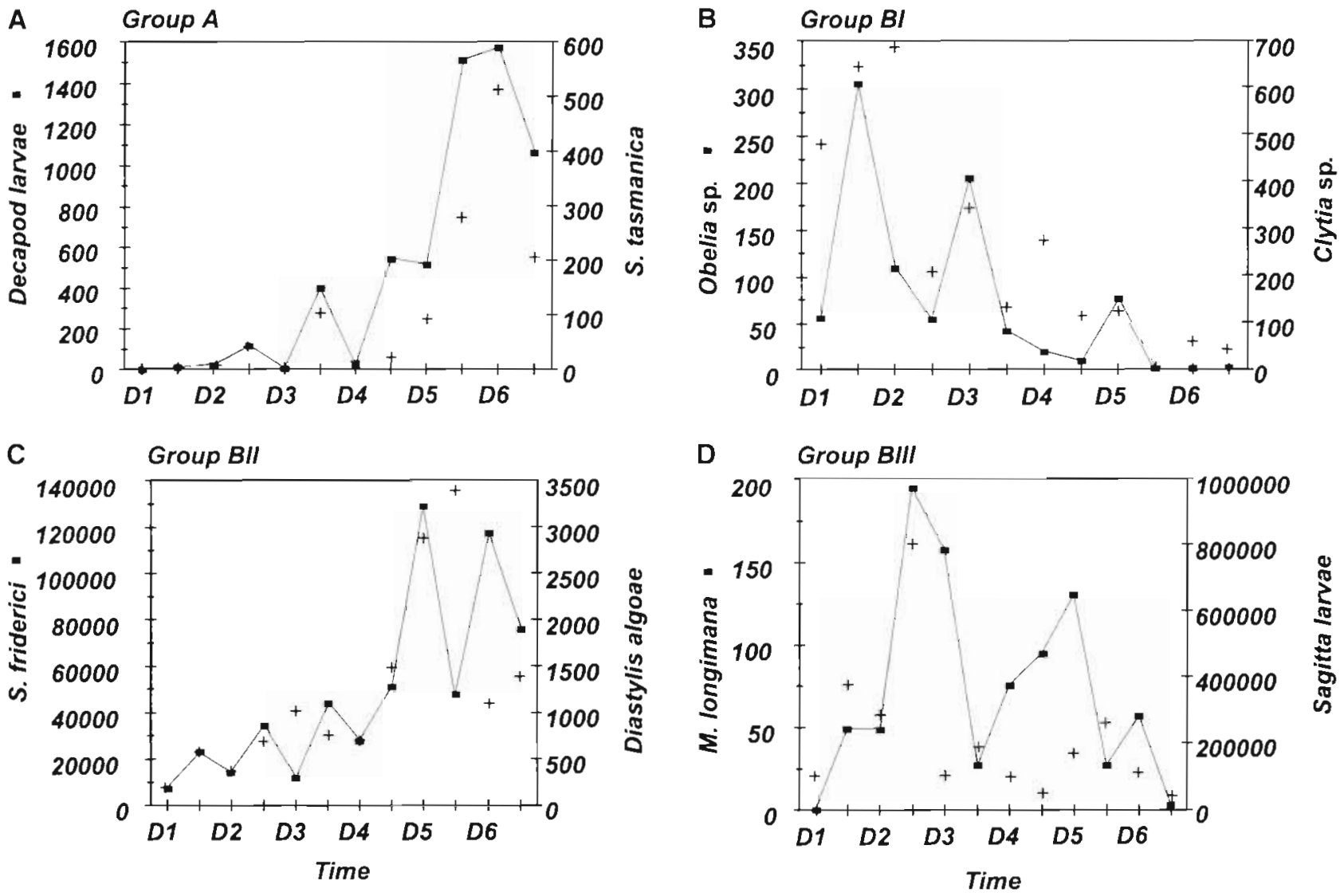

Fig. 6. Temporal changes in the abundance $\left(\mathrm{m}^{-2}\right)$ of taxa that are considered representative of each of the 4 groups identified in Fig. 5

ative persistence of the benthic and benthopelagic ${ }^{1}$ species of mysids, cumaceans and gammarid amphipods (Table 1; cf. Olivar \& Barange 1990).

The changes that were observed in the non-copepod zooplankton assemblage were not due to the mixing of different water types. Rather, the assemblage changed as the water mass moved gradually in a spiral fashion across the shelf. The initial assemblages were dominated by meroplankton and chaetognath larvae, while those at the end were characterised by large numbers of benthic and benthopelagic species. The progressive decrease in abundance of meroplankton may have been due to settlement, while the loss of chaetognath larvae can possibly be accounted for by adult recruitment, cannibalism (Pearre 1982) and predation.

\footnotetext{
Although some mysids, cumaceans and gammarids are known to be holoplanktonic (Mauchline 1980, Raymont 1983), the majority of species in these taxa are generally considered to be benthic (cumaceans and gammarids) or benthopelagic (mysids). There is no evidence to suggest that the species found in the southern Benguela region are holoplanktonic, and we have therefore considered these species to be benthic or benthopelagic here. Having said that, however, it is clear that these species are flexible in their choice of habitat
}

The gradual increase in abundance of other taxa (Groups A and BII) is clearly not the result of autochthonous succession, as none of these species have the requisite short generation times. Instead, it is postulated that these species moved (vertically) into the water column at night, but then failed to return to the benthos during the day. This hypothesis is supported by a number of lines of evidence. Firstly, the relative abundances of many of these species tended to increase at night (Fig. 6). In other words, these organisms were recruiting to the plankton at night. Secondly, if it is assumed that the mysids, gammarids and cumaceans were of benthic, or benthopelagic, origin then they must have moved into the water mass vertically. The nocturnal increase in the WMD for many of these species (Fig. 7) would then be caused by 'recruitment' to deep water from the seafloor. Although reverse diel vertical migration could also explain the increase in WMD at night, this is countered by the simultaneous increase in abundance. Thirdly, it must be remembered that the abundance of these species increased over the study period, which implies accumulation or a failure to return to the seafloor. 


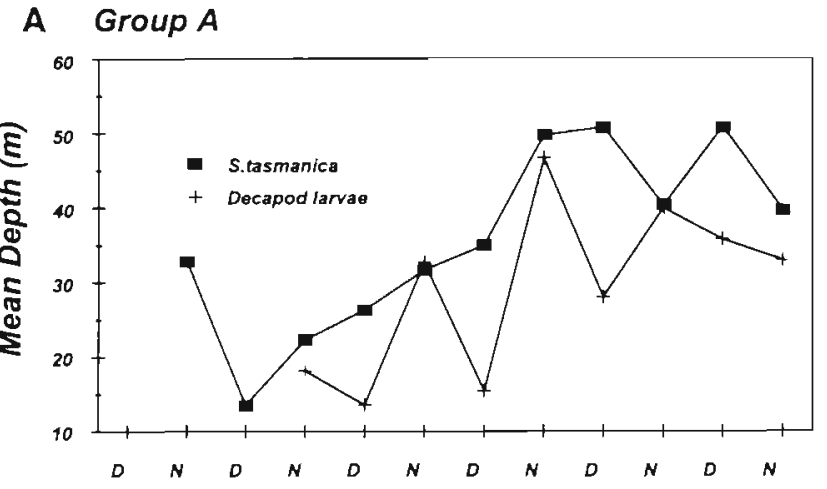

B Group BII

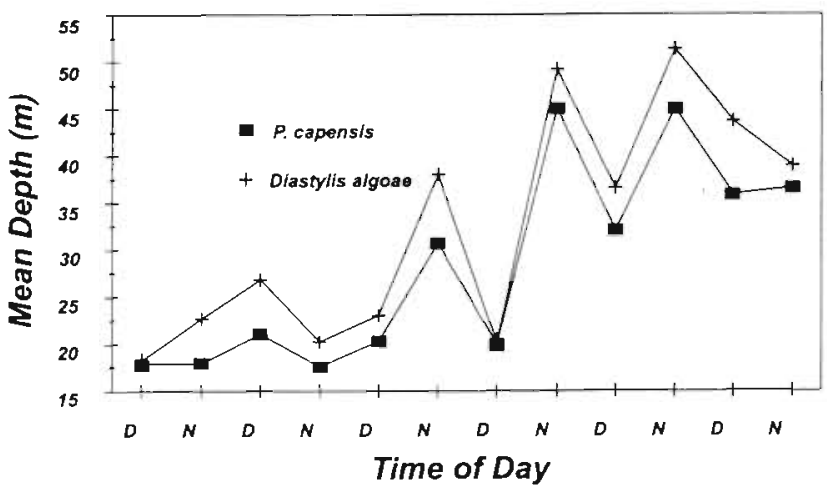

Fig. 7. Temporal changes in the mean depth of occupation for representative taxa from Groups A and BII identified in Fig. 5

Before an attempt is made to explain the failure of the zoobenthos to return to the seafloor, it is important to ask why these organisms should have moved up into the water column in the first place, and why at night

Jones (1955) noted the presence of large numbers of ovigerous females and adult males amongst a pelagic haul of cumaceans from the Benguela, which he interpreted (in part) as indicative of a nuptial swarm. Similar observations were made here with regard to the structure of the cumacean population (authors' unpubl. data). However, this explanation fails to account for the overall pattern, because the very high numbers of gammarid amphipods caught at the same time did not appear to be spawning. Indeed, no ovigerous gammarids were observed in the plankton. This suggests that some other, more generalised, factor may have been responsible for the presence of so many pelagic zoobenthos.

An alternative explanation for the nocturnal recruitment of the zoobenthos to the plankton may be sought in the fate of the overlying primary production. From concurrent work conducted by Kiørboe et al. (1998) and Tiselius \& Kiørboe (1998) it was apparent that little of the developing Chaetoceros spp. bloom was sedimenting out. Indeed, despite significant aggregation, fractional losses to the sediments were less than $0.005 \mathrm{~d}^{-1}$. These authors attributed this to the neutral buoyancy of the aggregates, and their in situ consumption by colonies of Noctiluca scintillans. Most cumaceans and gammarid amphipods are considered to be detritivores, and it is hypothesised that their presence in the water column might therefore have reflected food limitation. Upward vertical migration is exhibited by many planktonic and pelagic organisms at night and the behaviour reflects a balance between the need for food and a need to minimise predation risk (Gabriel \& Thomas 1988). It is not unreasonable, therefore, to suggest that suitably adapted benthic organisms might display a behaviour which is similar to that of planktonic organisms under conditions of low food.

Such an hypothesis is supported by changes in the vertical distribution of the phytoplankton aggregates through time. At the start of the study when the numbers of 'pelagic' benthic species were low, phytoplankton aggregates were distributed more or less evenly throughout water column (Fig. 7 in Kiørboe et al. 1998). However, by the end of the study most aggregates were concentrated in the upper $30 \mathrm{~m}$ (Fig. 7 in Kiørboe et al. 1998). Such a change may have caused not only an increase in the abundance of 'pelagic' benthic species, but might also have encouraged them to migrate as shallow as $30 \mathrm{~m}$ (Table 1). This argument is further strengthened by the fact that 1 of the benthic species, at least, was present in the water column with pigment-filled guts (Fig. 8A). Indeed, the cumacean Diastylis algoae had substantial amounts of pigment in its gut throughout the water column (Fig. 8B), 89.2\% (SD $8.2 \%, N=251)$ of which was phaeopigment. This suggests that for 1 species at least the individuals in the water column were feeding there.

An explanation for the failure of the zoobenthos to return to the seafloor during the day may be sought in the presence of low-oxygen water close to the bottom (Fig. 2B). The cyclical nature of the drogue track was such that inshore samples were collected during the day (Fig. 1), and it was these same inshore areas that were characterised by low-oxygen bottom water. In other words, there is a spatial element to the changes observed in the zooplankton assemblage.

The presence of low-oxygen bottom water was suggested by T. J. Hart to Jones (1955) in explanation of the high numbers of planktonic Cumacea observed in the Benguela. Low-oxygen water is characteristic of the region during late summer and autumn (Chapman \& Shannon 1985). Although one might expect local benthic species to be adapted to these conditions, the very seasonal nature of the low-oxygen events in the southern Benguela (as opposed to the northern Benguela; Bailey \& Rogers 1997) may preclude this, unless such events are gradual and the organisms have 

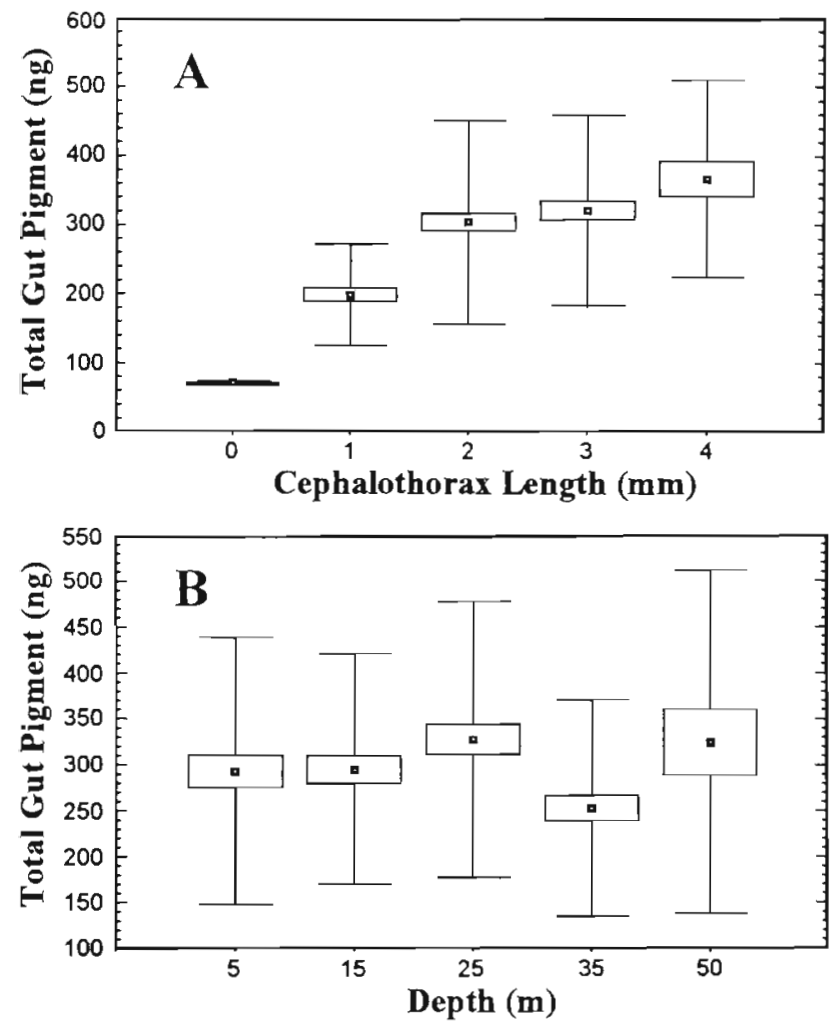

Fig. 8. Box-and-whisker plots (mean, SE and SD) showing variations in the total gut-pigment content of the cumacean Diastylis algoae (ng ind. ${ }^{-1}$ ) with (A) individual size and (B) depth of capture. $N=324$ in all cases. Gut-pigment data calculated as fluorescence using the method of Dagg \& Walser (1987) and Gibbons (1993). It is assumed that individuals with little or no pigment in their guts represented individuals with empty guts

time to acclimate. Unfortunately, data to support this are missing. Certainly, water with very low concentrations of dissolved oxygen are associated with the mass mortality of some nearshore benthic invertebrates such as the crayfish Jasus lalandii (De Decker 1970, Newman \& Pollock 1977). However, the levels of oxygen observed were obviously not low enough to influence the distribution of some holozooplankton such as Sagitta tasmanica (Fig. 7A).

Interestingly, high densities of zooplankton have been observed in the deep (>400 m), low-oxygen water $\left(<0.2 \mathrm{ml} \mathrm{l}^{-1}\right)$ that occurs seasonally on the Californian shelf by Longhurst (1967), and it is clear that some benthopelagic species have respiratory adaptations that allow them to survive there (e.g. Childress 1971). Longhurst (1967) noted significant upward vertical movement of some zooplankton from oxygenpoor waters at night. He explained such movements as adaptive, where oxygen-rich water was present at the surface, and such an hypothesis needs little modification to be applied in this case to the zoobenthos.
In summary then, the results suggest that as the upwelled water mass moved offshore, the composition of the non-copepod zooplankton assemblage changed in a spatio-temporal manner. The changes were partly due to the 'emigration' (settlement and growth) of the initial colonisers, and a combination of vertical recruitment and subsequent accumulation of 'immigrant' species from the benthos and deeper water. It is hypothesised that the poor food supplies to the benthos encouraged the various amphipods, mysids and cumaceans to migrate upwards at night, and recruit to the plankton. These immigrants failed to return to the benthos during the day because of the presence of lowoxygen bottom water, over which the organisms then found themselves.

There are almost no studies which can be usefully compared to the present one, although Verheye (1991) conducted a $28 \mathrm{~d}$ anchor-station study in St Helena Bay during late summer 1987. The results of their work indicated that the relative composition of the non-copepod zooplankton assemblage remained unchanged, despite some significant changes in the physical structure of the water column caused by pulsed upwelling events. Interestingly, however, Verheye (1991) noted only low numbers of cumaceans and other benthic invertebrates in the water column, even though the concentration of dissolved oxygen in the bottom water was also less than $0.5 \mathrm{ml} \mathrm{l}^{-1}$. This suggests that the presence of low-oxygen bottom water, on its own, need not lead to an accumulation of zoobenthos in the water column, although these authors did not study the sedimentation of phytoplankton.

Acknowledgements. We would like to thank the officers and crew of the FRS 'Africana' for their co-operation and assistance in the field. Grateful thanks are owed to Thomas Kiorboe and Peter Tiselius for sharing their data with us, and to Larry Hutchings and some anonymous referees, who, with the aforementioned persons, commented on various drafts of the manuscript. We would like to acknowledge Charles Griffiths, Masaaki Murano and Jenny Day for identifying the gammarid amphipods, mysids and cumaceans, respectively. Financial support for M.J.G. and N.G. originated from the Benguela Ecology Programme of the Foundation for Research Development and from the University of the Western Cape.

\section{LITERATURE CITED}

Bailey GW, Chapman P (1991) Short-term variability during an anchor station study in the southern Benguela upwelling system: chemical and physical oceanography. Prog Oceanogr 28:9-37

Bailey GW, Rogers J (1997) Chemical oceanography and marine geoscience of southern Africa: past discoveries in the post-Gilchrist era and future prospects. Trans R Soc S Afr 52:51-79

Boyd AJ (1982) Small-scale measurements of vertical shear 
and rates of horizontal diffusion in the southern Benguela Current. Fish Bull S Afr 16:1-9

Boyd AJ (1983) Intensive study of the currents winds and hydrology at a coastal site off central South West Africa June/July 1978. Invest Rep Sea Fish Res Inst S Afr 126: $1-47$

Carr MR (1997) PRIMER user manual (Plymouth Routines in Multivariate Ecological Research). Plymouth Marine Laboratory, Plymouth

Chapman P. Shannon LV (1985) The Benguela ecosystem. Part II. Chemistry and related processes. Oceanogr Mar Biol Annu Rev 23:183-251

Childress JJ (1971) Respiratory adaptations to the oxygen minimum layer in the bathypelagic mysid Gnathophausia ingens. Biol Bull 1.41:109-121

Clarke KR, Warwick RM (1994) Change in marine communities: an approach to statistical analysis and interpretation. Plymouth Marine Laboratory, Plymouth

Dagg MJ, Walser WE (1987) Ingestion gut passage and egestion by the copepod Neocalanus plumchrus in the laboratory and in the subarctic Pacific Ocean. Limnol Oceanogr 32:178-188

De Decker AHB (1970) Notes on an oxygen depleted subsurface current off the west coast of South Africa. Invest Rep Div Fish S Afr 84:1-24

Flock ME, Hopkins TL (1.992) Species composition vertical distribution and food habits of the sergestid shrimp assemblage in the eastern Gulf of Mexico. J Crustac Biol 12: $210-233$

Gabriel W. Thomas B (1988) Ultimate causes of vertical migration in zooplankton: an evaluation by evolutionary game theory. In: Wolff W, Soeden CJ, Dreppen FR (eds) Ecodynamics. Contributions to theoretical ecology. Springer, Berlin, p 127-134

Gibbons MJ (1993) Vertical migration and feeding of Euphausia lucens at two $72 \mathrm{~h}$ stations in the southern Benguela upwelling region. Mar Biol 116:257-268

Gibbons MJ, Hutchings L (1996) Zooplankton diversity and community structure around southern Africa with special attention to the Benguela upwelling system. S Afr J Sci 92 $63-76$

Gibbons MJ, Stuart V, Verheye HM (1992) Trophic ecology of carnivorous zooplankton in the Benguela. S Afr J Mar Sci $12: 421-437$

Hayward TL (1980) Spatial and temporal feeding patterns of copepods from the north Pacific central gyre. Mar Biol 58: 295-309

Hayward TL (1986) Variability in production and the role of disturbance in two pelagic ecosystems. In: Pierrot-Bults AC, van der Spoel S, Zahuranec BJ, Johnson RK (eds) Pelagic biogeography. UNESCO Tech Pap Mar Sci 49: $133-140$

Hopkins TL, Gartner JV, Flock ME (1989) The caridean shrimp (Decapoda: Natantia) assemblage in the mesopelagic zone of the eastern Gulf of Mexico. Bull Mar Sci 45: $1-14$

Hutchings L (1988) Horizontal distribution of mesozooplank ton in the southern Benguela Current 1969-1974. Invest Rep Sea Fish Res Inst S Afr 131:1-70

Hutchings L (1992) Fish harvesting in a variable productive

Editorial responsibility: Otto Kinne (Editor),

Oldendorf/Luhe, Germany environment - searching for rules or searching for exceptions? S Afr J Mar Sci 12:297-318

Jones NS (1955) Cumacea of the Benguela current. Discovery Rep 27:281-291

Kiørboe T, Tiselius P, Mitchell-Innes B, Hansen JLS, Visser AW, Mari X (1998) Intensive aggregate formation with low vertical flux during an upwelling induced diatom bloom. Limnol Oceanogr 43:104-116

Longhurst A (1967) Vertical distribution of zooplankton in relation to the eastern Pacific oxygen minimum. Deep-Sea Res 14:51-63

Mauchline J (1980) The biology of mysids and euphausiids. Adv Mar Biol 18:1-681

McGowan JA, Walker PW (1979) Structure in the copepod community of the north Pacific gyre. Ecol Monogr 49:195-226

Nelson G (1989) Poleward motion in the Benguela Area. In Neshyba SJ, Mooers CNK, Smith RL, Barber RT (eds) Poleward flows along eastern ocean boundaries. Springer, New York, p 110-130

Newman GG, Pollock DE (1977) The population dynamics of the rock lobster Jasus lalandii on two South African fishing grounds. Coll Sci Pap Int Comm SE Atl Fish 4:175-187

Olivar MP, Barange M (1990) Zooplankton of the Northern Benguella region in a quiescent upwelling period. J Plankton Res 12:1023-1044

Pagés F (1992) Mesoscale coupling between planktonic cnidarian distribution and water masses during a temporal transition between active upwelling and abatement in the northern Benquela system. S Afr J Mar Sci 12:41-52

Pagés F, Verheye HM, Gili JM, Flos J (1991) Short-term effects of coastal upwelling and wind reversals on assemblages of epiplanktonic cnidarians in the southern Benguela region. S Afr J Mar Sci 10:203-212

Parsons TR, Maita Y, Lalli CM (1984). A manual of chemical and biological methods for seawater analysis. Pergamon, New York

Pearre S (1973) Vertical migration and feeding in Sagitta elegans Verrill. Ecology 54:300-314

Pearre S (1982) Feeding by chaetognatha: aspects of interand intra-specific predation. Mar Ecol Prog Ser 7:33-45

Pitcher GC, Walker DR, Mitchell-Innes BA, Moloney CL (1991) Short term variability during an anchor station study in the southern Benguela upwelling ecosystem: phytoplankton dynamics. Prog Oceanogr 28:39-64

Pitcher GC, Brown PC, Mitchell-Innes BA (1992) Spatio-temporal variability of phytoplankton in the southern Benguela upwelling system. S Afr J Mar Sci 12:439-456

Raymont JEG (1983) Plankton and productivity in the oceans. 2. Zooplankton. Pergamon, Oxford

Shannon LV (1985) The Benguela ecosystem. J. Evolution of the Benguela, physical features and processes. Oceanogr Mar Biol Annu Rev 23:105-182

Tiselius P, Kiørboe T (1998) Colonisation of diatom aggregates by the dinoflagellate Noctiluca scintillans. Limnol Oceanogr 43:154-159

Verheye HM (1991) Short-term variability during an anchor station study in the southern Benguela upwelling system: abundance distribution and estimated production of mesozooplankton with special reference to Calanoides carinatus (Kroyer 1849). Prog Oceanogr 28:91-119

Submitted: June 15, 1998; Accepted: December 23, 1998

Proofs received trom author(s): April 19, 1999 